\title{
Childhood Langerhans Cell Histiocytosis with Risk Organ Involvement
}

National Cancer Institute

\section{Source}

National Cancer Institute. Childhood Langerhans Cell Histiocytosis with Risk Organ

Involvement. NCI Thesaurus. Code C123395.

Langerhans cell histiocytosis that occurs during childhood and involves the bone marrow, spleen, liver, or lung. 